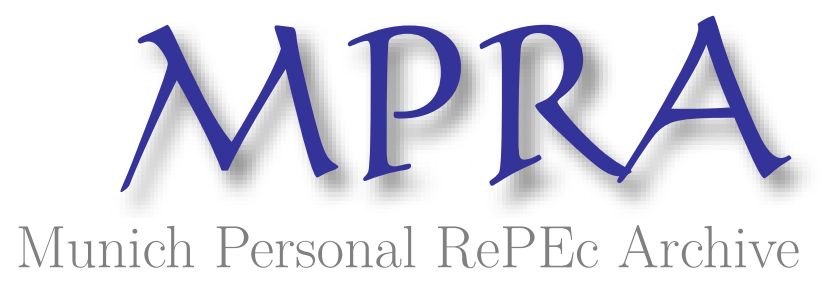

\title{
A Class of Dynamic Demand Systems
}

Tian, Guoqiang and Chipman, John S.

1989

Online at https://mpra.ub.uni-muenchen.de/41387/

MPRA Paper No. 41387, posted 17 Sep 2012 13:35 UTC 


\section{A CLASS OF DYNAMIC DEMAND SYSTEMS*}

\section{GUOQIANG TIAN \\ Texas A\&M University \\ Department of Economics \\ College Station \\ TX 77843-4228}

\author{
JOHN S. CHIPMAN \\ University of Minnesota \\ Department of Economics \\ Minneapolis \\ MN 55455
}

ABSTRACT. This paper derives closed-form solutions for the total consumption-expenditure function (i.e., aggregate consumption function), the savings function and the demand functions from a nonstationary intertemporal utility-maximization problem under uncertainty for a class of demand systems, including the linear expenditure system (LES) from the Klein-Rubin-Samuelson (KRS) utility Systems, including the linear expenditure system (LES) from the Klein-Rubin-Samuelson (KRS) utily
function, the generalized linear expenditure systems (GLES) from the CES and S-branch-tree utility function, the generalized linear expenditure systems (GLES) from the CES and S-branch-tree utilty
functions, the Almost Ideal Demand System (AIDS) from the PIGLOG class of preferences, and the functions, the Almost Ideal Demand System (AIDS) from the PIGLOG class of preferences, and the
indirect addilog demand system (IADS). We do so by following Hicks' and Tintner's method of indirect addilog demand system (IADS). We do so by following Hicks' and Tintner's method of method of maximizing an expected discounted utility function subject to stochastic constraints. Furthermore, the preferences are allowed to vary with the time period. Theoretical analyses for these systems are also given in this paper.

\section{Introduction}

Since the linear expenditure system (LES) was first studied by Stone (1954), many analyses of demand systems have been undertaken and many models have been proposed for alternative specifications and functional forms (see, e.g., Christensen, Jorgenson, and Lau 1975, Deaton and Muellbauer 1980, Theil 1965, 1976). These models have been widely used in applications of demand theory as well as in intemational trade (cf. Powell 1966, Parks 1969, Pollak and Wales 1969, Goldberger and Gamaletsos 1970, Musgrove 1974, Anderson and Browning 1986, Chipman 1985). A number of generalizations of these models have been provided (Johansen 1969, Wales 1971, Brown and Heien 1972, Lluch 1973, 1974, Howe 1975, and Musgrove 1977). Estimation methods for these systems have been worked out (Barten 1969, Pollak and Wales 1969, Parks 1971, Powell 1973, Howe 1974, MacKinnon 1976, Blackorby, Boyce, and Russell 1978, Woodland 1979, Ronning 1983, Wales and Woodland 1983, and Chipman and Tian 1988a, 1988b).

Almost all of the above-mentioned studies treat total consumption expenditure as exogenously given and make no attempt to analyze the consumption-savings decision. The modern intertemporal utility-maximizing model is usually put at Ramsey's 1928 article on optimal saving (1928). Tintner $(1938 \mathrm{a}, 1938 \mathrm{~b})$ considered formally the general intertemporal problem of faced by a consumer with given expectations about prices, income, and interest rate both in discrete time and continuous time as a theoretical tool (see also Hicks 1935, 1939). However, he did not attempt to specialize the utility function. Empirical implementation did not appear until the work 
of Modigliani and Brumberg (1954) (who used a one-commodity assumption) and Lluch (1973). Lluch is the first to extend the LES into an intertemporal maximization problem over continuous time, subject to an expected-wealth constraint, and to derive the expenditure equations and the aggregate consumption function. However, Lluch's approach assumes that the commodity prices and the interest rate on non-human wealth and the shift-parameters are constant over the time path. This is clearly not a suitable assumption. Also it is well known that the (dynamic) LES embodies some undesirable restrictions so that it is necessary to develop alternative dynamic demand systems (such as the dynamic GLES and the dynamic AIDS) which would be of greater interest to applied workers.

In order to avoid the assumption of perfect foresight, two quite different approaches have been followed in the literature. The first - which is the more fashionable one in the current literature (cf. Hall 1978, MaCurdy 1983, Sargent 1987) - is to maximize an expected utility function (i.e., the expectation of the present value of future instantaneous utilities) subject to a set of stochastic constraints. This approach is based on the axioms of von Neumann and Morgenstern (1947), and in particular on the crucial 'independence axiom' that was later brought out explicitly by Marschak (1950) and Samuelson (1953). The empirical realism of this axiom has been challenged by a number of writers, starting with Wold (1952) and Allais (1953), and more recently by Kahneman and Tversky (1979), Machina (1982), and Yaari (1987), who have proposed alternative sets of postulates. A further criticism has been raised by Ben-Tal and Ben-Israel (1987), namely that it allows realized values of decision variables to violate stochastic inequality constraints. A final, practical, drawback of the expected-utility approach is that closed-form solutions for decision functions cannot in general be obtained, unless very specific assumptions are made concerning the instantaneous utility functions and uncertainty (cf. e.g., Epstein and Wolpin 1988).

The second approach is an older one due to Hicks $(1935,1939)$ and Tintner $(1938 \mathrm{a}, 1938 \mathrm{~b})$; followers are Lluch (1973, 1974), Lluch and Morishima (1973), Powell (1973, 1974), Howe (1974, 1975), and Musgrove $(1974,1977)$. In this approach the instantaneous utility functions are assumed to be nonstochastic in the parameters, and the intertemporal utility-maximization problem is to maximize a discounted utility function (the expectation of the present value of future instantaneous utilities) subject to expected constraints, i.e., subject to given expectations about prices, income, and interest rate over time. It is known (cf. Simon 1956. Theil 1954, 1957) that a sufficient condition for the von Neumann-Morgenstern approach to reduce to the HicksTintner approach, i.e., for each random variable to have a 'certainty equivalent', is that the instantaneous utility functions be quadratic and the constraints be linear in the random variables and decision variables (cf. Sargent 1979, p. 346). Under these conditions the mathematical expectation can be taken 'inside' the marginal utility function, i.e., $E_{t} u^{\prime}(x(t))=u^{\prime}\left(E_{t} x(t)\right)$. Whether and under what circumstances this condition is also necessary appears to be an open question. Another condition that would justify the Hicks-Tintner approach is the existence of perfect markets permitting hedging and insurance; for, if the consumer's instantaneous utility function $u(x)$ is concave, $E_{t} u(x(t)) \leqq u\left(E_{t} x(t)\right)$ by Jensen's inequality. We do not pretend in this paper to have axiomatic foundations for the Hicks-Tintner approach, but follow it for more pragmatic reasons: (1) it permits closed-form solutions for general classes of preferences, and is thus amenable to practical application; and (2) the expected-utility approach, which does not permit closed-form solutions except for special types of preferences and constraints, does not have strong empirical support, and indeed has been increasingly called into question in empirical research.

This paper deals with the discrete intertemporal consumption-maximization problem under uncertainty using the Klein-Rubin-Samuelson (KRS) utility function, the CES utility function, the Brown-Heien S-branch-tree utility function which is a modification of Sato's two-level CES production function, from which the LES and the generalized linear expenditure systems (GLES) are derived, and further, the PIGLOG class of preferences resulting in the AIDS (see Deaton and Muellbauer 1980). The demand functions together with the savings function as well as the endogenous total consumption expenditure associated with the LES, the GLES, and the AIDS are called the dynamic linear expenditure system (DLES), the dynamic generalized linear expenditure systems (DGLES), and the dynamic AIDS (DAIDS) respectively. In addition, we also derive the dynamic indirect addilog demand system (DIADS) with $b_{i}$-parameter identical among goods.

In the context of these dynamic demand systems, we can answer questions about the responses of the consumption, savings, and demand functions to changes in the interest factor, expected labor income, the expected prices and the last-period savings. The signs of the derivatives of the minimum expenditure $-d(p(t))$ are crucial to determining the signs of the derivatives of the optimal decision functions with respect to prices. For instance, when $\frac{\partial d(p(t))}{\partial p_{i}(t)}$ is positive, an increase in the current price of the $i$ th commodity will lead to increases in the current-period savings and to a decrease in the current total consumption expenditure; an increase in expected future prices will lead to decreases in current savings and to increases in total consumption expenditure if $\frac{\partial d(p(t+s))}{\partial p_{i}(t+s)}$ is positive $(s>0)$. When $\frac{\partial d(p(t+s))}{\partial p_{i}(t+s)}$ is negative $(s \geqq 0)$, the conclusions are reversed. Thus we can see that the assumption made by Lluch (1973), that prices of commodities are constant over the time path, may not be suitable. Also his assumption that the interest rate is constant over the time path may not be suitable because, as we shall show later, an increase in the last-period interest rate causes the current-period savings, current demands and total consumption expenditure to increase only if the consumer had been lending in the last period.

Our approach presented here has a number of advantages. We know that intertemporal analysis has been widely used in macro-economic models of the balance of payments in intemational trade. Owing, however, to the considerable mathematical difficulties involved, theoretical contributions (see, e.g., Lucas 1982), have adopted a one-commodity assumption and/or have neglected production. Even so, empirical applications to international trade or macro models have been rare. Our approach here offers a way to derive the consumption-savings decision functions with many commodities so that we can easily carry out the theoretical analysis and empirical applications. More realistically, we allow the model to be nonstationary in instantaneous preferences, i.e., the instantaneous preferences of the consumer vary over time periods. In fact, for any instantaneous utility function, if its indirect utility function is log-linear or is quadratic in total consumption expenditure, we can easily derive the savings-decision functions by solving the Euler equation; then wc can derive the demand functions by solving the consumer's static maximization problem. Since the indirect utility functions associated with these dynamic demand systems are log-linear in the total consumption expenditure $c(t)$, the functional forms of the consumption-savings decision functions for these utilities are the same, while only the demands are different.

The plan of the paper is as follows. Section 2 sets forth a general form of the consumer's intertemporal maximization problem and derives closed-form solutions of the consumptionsavings functions for a class of preferences. In Section 3, the DLES, the DGLES, the DAIDS, and the DIADS are derived. In Section 4, we carry out a theoretical analysis of the optimal decision functions. In Section 5, further assumptions are made so that we can simplify the formulas for the optimal decision functions. In Section 6, some conclusions and remarks are presented. 


\section{The General Intertemporal Consumer Problem}

The basic variables of the model are indicated by the following notation ( $l$ denotes time):

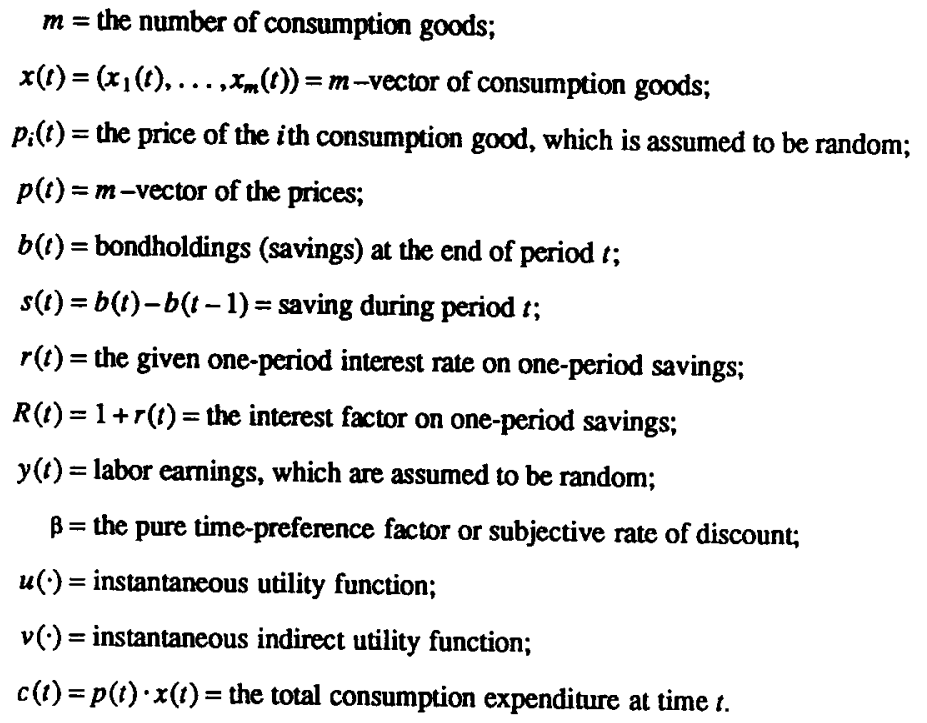

Remark 1. In order to avoid the assumption of perfect foresight, we assume that the distribution of the random prices and labor income are known (this is the rational-expectations hypothesis). Then at time $t$, the expected future prices and labor income are denoted by

$$
\begin{aligned}
& p(t, t+j)=E_{t} p(t+j) \\
& y(t, t+j)=E_{t} y(t+j)
\end{aligned}
$$

for $j=1,2, \ldots, \infty$, where $E_{t}$ denotes the mathematical expectation conditional on the information set available at time $t$.

In the following, we adopt the Hicks-Tintner approach to the intertemporal problem of a consumer faced with given expectations about prices and income. That is, we assume that the
consumer's problem at $t=0$ is

$$
\max \sum_{t=0}^{\infty} \beta^{\prime} u(x(t))
$$

subject to

$$
E_{0}[(p(t)) \cdot x(t)+b(t)]=E_{0}[y(t)+R(t-1) b(t-1)]
$$

with $b(-1)$ given.' Writing (1) in another way, we have

$$
E_{0}[p(t) \cdot x(t)+s(t)]=E_{0}[y(t)+r(t-1) b(t-1)] .
$$

This states that that the expected value (conditional on the information at time 0 ) of consumption plus saving in period $t$ is equal to the expected value of labor income plus property income at time $t$. The period utility function $u(\cdot)$ is assumed to be twice-continuously differentiable, and
increasing in each argument.

\section{A CLASS OF DYNAMIC DEMAND SYSTEMS}

In addition to the above constraint, the terminal condition (or borrowing constraint)

$$
\lim _{t \rightarrow \infty} \Phi(t)^{-1} \Phi(t+j) b(t+j)=0
$$

is needed to prevent the consumer from borrowing arbitrarily large amounts, where

$$
\Phi(t)=\prod_{\tau=0}^{t-1} R(\tau)^{-1}
$$

The interpretation for (2) is that the present value of borrowing goes to zero, or equivalently, debt does not grow at a rate exceeding the interest rate.

Remark 2. The terminal condition (2) and the budget constraint (1) are equivalent to a lifetime budget constraint which can be written in terms of the following stock balance:

$$
E_{0} \sum_{t=0}^{\infty} \Phi(t) p(t) \cdot x(t)=E_{0} \sum_{t=0}^{\infty} \Phi(t) y(t) .
$$

This states that the present value of planned expenditures should equal the present value of earned income (cf. Chipman and Tian 1988c).

Let the indirect utility function be defined by

$$
v(p(t), c(t))=\max \{u(x(t)): p(t) \cdot x(t)=c(t)\} .
$$

Then the maximization problem at $t=0$ becomes

$$
\max \sum_{t=0}^{\infty} \beta^{t} v(p(0, t), c(t))
$$

subject to

$$
E_{0}\left[(c(t)+b(t)]=E_{0}[y(t)+R(t-1) b(t-1)]\right.
$$

This is because after we obtain the solution for $c(t)$ and $b(t)$, we can obtain the demand functions by the Antonelli-Allen-Roy partial differential equation

$$
x_{i}(t)=-\frac{\frac{\partial v(p(t), c(t))}{\partial p_{i}(t)}}{\frac{\partial v(p(t), c(t))}{\partial c(t)}} .
$$
In general, it is very difficult to derive the optimal solution of (3) even though we can analyze its
existence and properties by using discounted dynamic programming. Empirical applications have been rare for this reason in the discrete-time problem.

In order to discover necessary conditions for (3) it is convenient to consider the finite-horizon problem:

$$
\max \sum_{i=0}^{T} \beta^{t} v\left(E_{0} p(t), E_{0}[y(t)+R(t-1) b(t-1)-b(t)]\right)
$$

with $b(-1)$ given and $\Phi(T) b(T)=0$ (or equivalently, $b(T)=0$ ). This problem matches our infinitehorizon problem when $T$ goes to infinity. Then the Euler equation (first-order necessary condition) 
is obtained by differentiating (4) with respect to $b(t)$ :

$$
\begin{aligned}
& -\beta^{t} v_{c}(p(t), y(t)+R(t-1) b(t-1)-b(t))+ \\
& +\beta^{t+1} R(t) v_{c}\left(E_{t} p(t+1), E_{t}[y(t+1)+R(t) b(t)-b(t+1)]\right)=0
\end{aligned}
$$

for $t=0,1,2, \ldots, T-2$, and

$$
\begin{aligned}
& -\beta^{T-1} v_{c}(p(T-1), y(T-1)+R(T-2) b(T-2)-b(T-1))+ \\
& +\beta^{T} R(T-1) v_{c}\left(E_{T-1} p(T), E_{T-1}[y(T)+R(T-1) b(T-1)]\right)=0
\end{aligned}
$$

for $t=T-1$.

The latter is the terminal condition of the Euler equation (known as the transversality condition) and is a necessary condition for optimality. To obtain the terminal condition in the infinitehorizon problem, it is appropriate to take

$$
\begin{aligned}
& \lim _{T \rightarrow \infty} \beta^{T-1}\left[-v_{c}(p(T-1), y(t-1)+R(T-2) b(T-2)-b(T-1))+\right. \\
& \left.+\beta R(T-1) v_{c}(p(T), y(T)+R(T-1) b(T-1))\right]=0 .
\end{aligned}
$$

To obtain closed-form solutions for the optimal decision functions, we assume that the instantaneous indirect utility function is of the form ${ }^{2}$

$$
v_{t}(p(t), c(t))=\log g_{t}(p(t))+b \log \left[c(t)+d_{t}(p(t))\right]
$$

where $d_{t}(p(t))$ is a linear homogeneous function of within-period prices. $-d_{t}(p(t))$ can be regarded as the cost of subsistence or minimum-required expenditure.

In the following sections, we will see that several indirect utility functions which are widely used in the demand-system literature have this form; these include the Klein-Rubin-Samuelson (KRS) utility function whose maximization leads to the LES, the CES utility and Brown-Heien S-branch utility tree which are both generalizations of the LES, the PIGLOG class preferences resulting in the AIDS, and Houthakker's (1960) indirect addilog utility function. Note that we allow the preferences of the consumer to change with time periods.

In order to guarantee the existence of the solutions, we assume $R(t)>1, \beta R(t)<1$ for $t=0,1,2, \ldots, \infty$ and

$$
\lim _{t \rightarrow \infty} \Phi(t)\left[d_{t}(p(t))+y(t)\right]=0
$$

Since

$$
v_{c}(p(t), c(t))=\frac{b}{c(t)+d_{t}(p(t))},
$$

the Euler equation (5) becomes

$$
-\frac{\beta^{t} b}{\xi(t)+R(t-1) b(t-1)-b(t)}+\frac{\beta^{t+1} R(t) b}{E_{t}[\xi(t+1)+R(t) b(t)-b(t+1)]}=0
$$

or

$$
E_{t} b(t+1)-(1+\beta) R(t) b(t)+\beta R(t) R(t-1) b(t-1)=E_{t} \xi(t+1)-\beta R(t) \xi(t),
$$

where

$\xi(t)=d_{t}(p(t))+y(t)$

\section{A CLASS OF DYNAMIC DEMAND SYSTEMS}

The transversality condition (6) becomes

$$
\begin{aligned}
& \lim _{T \rightarrow-\infty} \beta^{T-1}[-(1+\beta) R(T-1) b(T-1)+\beta R(T-1) R(t-2) b(T-2)- \\
& -\xi(T)+\beta R(T-1) \xi(T-1)=0 .
\end{aligned}
$$

The transversality condition holds under the given assumptions. In fact, from $\lim _{\tau \rightarrow \infty} \beta^{T} b(T)=\lim _{T \rightarrow \infty}\left(\prod_{\tau=0}^{T-1} \beta R(\tau)\right)(\Phi(T) b(T))=0 \quad$ and $\quad \lim _{\tau \rightarrow \infty} \beta^{T} \xi(t)=\lim _{T \rightarrow \infty}\left(\prod_{\tau=0}^{T-1} \beta R(\tau)\right)(\Phi(T) \xi(T))=0, \quad$ we know that the limit of each term of (9) goes to zero as $t \rightarrow \infty$. This shows that the transversality condition holds. In order to solve (8) for $b(t)$, we first assume that $R(t) \equiv R$. Then $(8)$ becomes

$$
E_{t} b(t+1)-(1+\beta) R b(t)+\beta R^{2} b(t-1)=E_{t} \xi(t+1)-\beta R \xi(t) .
$$

Define the lag operator $L$ and its inverse operator $L^{-1}$ by

$$
L b(t)=b(t-1)
$$

and

$$
L^{-1} b(t)=E_{t} b(t+1)
$$

The (10) can be written as

$$
\left(L^{-1}-(1+\beta) R+\beta R^{2} L\right) b(t)=E_{t} \xi(l+1)-\beta R \xi(t)
$$

The characteristic equation is

$$
\lambda^{2}-(1+\beta) R \lambda+\beta R^{2}=0
$$

whose roots are $\lambda_{1}=R$ and $\lambda_{2}=\beta R$. Therefore we can write (11) as

$$
-\lambda_{1}\left(1-\lambda_{1}^{-1} L^{-1}\right)\left(1-\lambda_{2} L\right) b(t)=E_{t} \xi(t+1)-\beta R \xi(t) .
$$

The general solution of the above difference equation is

$$
\begin{aligned}
\left(1-\lambda_{2} L\right) b(t) & =\frac{-\lambda_{1}^{-1}}{1-\lambda_{1}^{-1} L^{-1}}\left(E_{t} \xi(t+1)-\beta R \xi(t)\right)+A R^{t} \\
& =-R^{-1} \sum_{j=0}^{\infty} R^{-j} E_{t}(\xi(t+1+j)-\beta R \xi(t+j))+A R^{t} \\
& =-\sum_{j=0}^{\infty} R^{-(j+1)} E_{t} \xi(t+1+j)+\beta \sum_{j=0}^{\infty} R^{-j} E_{t} \xi(t+j)+A R^{t} \\
& =\beta \xi(t)-(1-\beta) \sum_{j=0}^{\infty} R^{-j} E_{t} \xi(t+j)+A R^{t}
\end{aligned}
$$

where $A$ is a constant. However, since $R>1$, we must have $A=0$ in order to satisfy the borrowing constraint (2), for the above equation can be written as

$$
A=R^{-t} b(t)-\beta R^{-(t-1)} b(t-1)-\beta R^{-t} \xi(t)+(1-\beta) \sum_{j=0}^{\infty} R^{-(t+j)} E_{t} \xi(t+j)
$$

of which each term on the right goes to zero as $t$ goes to infinity. Setting $A=0$, we have 


$$
b(t)=\beta R b(t-1)+\beta \xi(t)-(1-\beta) \sum_{j=1}^{\infty} R^{-j} E_{t} \xi(t+j) .
$$

Now we consider the general case where $R(t)$ is not constant. We guess that the solution of (8) is of the form

$$
b(t)=\beta R(t-1) b(t-1)+\beta \xi(t)-(1-\beta) \sum_{j=1}^{\infty} \prod_{\tau=0}^{j-1} R(t+\tau)^{-1} E_{t} \xi(t+j)
$$

and thus

$$
b(t+1)=\beta R(t) b(t)+\beta \xi(t+1)-(1-\beta) \sum_{j=1}^{\infty} \prod_{\tau=0}^{j-1} R(t+1+\tau)^{-1} E_{t+1} \xi(t+1+j)
$$

for $t=0,1,2, \ldots, \infty$. Now we verify that (12) is the solution of (8). In fact, using (12) - (13) and that fact that $E_{t} E_{t+1} f(t+j)=E_{v} f(t+j)$ for any integral function $f(\cdot)$ and $j \geq 0$, we have

$$
\begin{aligned}
& E_{t} b(t+1)-(1+\beta) b(t) R(t)+\beta R(t) R(t-1) b(t-1) \\
&=\beta R(t) b(t)+\beta E_{t} \xi(t+1)-(1-\beta) \sum_{j=1}^{\infty} \Phi(t+1)^{-1} \Phi(t+1+j) E_{t} \xi(t+1+j)- \\
&-\beta R(t) b(t)-R(t) b(t)+\beta R(t) R(t-1) b(t-1) \\
&=-R(t) b(t)+\beta R(t) R(t-1) b(t-1)+\beta E_{t} \xi(t+1)-(1-\beta) \sum_{j=1}^{\infty} \Phi(t+1)^{-1} \Phi(t+1+j) E_{t} \xi(t+1+j) \\
&=-R(t)\left(\beta R(t-1) b(t-1)+\beta \xi(t)-(1-\beta) \sum_{j=1}^{\infty} \Phi(t)^{-1} \Phi(t+j) E_{t} \xi(t+j)\right)+ \\
&+\beta R(t) R(t-1) b(t-1)+\beta E_{t} \xi(t+1)-(1-\beta) \sum_{j=1}^{\infty} \Phi(t+1)^{-1} \Phi(t+1+j) E_{t} \xi(t+1+j) \\
&=\beta E_{t} \xi(t+1)-\beta R(t) \xi(t)+(1-\beta) \sum_{j=1}^{\infty} \Phi(t+1)^{-1} \Phi(t+j) E_{t} \xi(t+j)- \\
&-(1-\beta) \sum_{j=1}^{\infty} \Phi(t+1)^{-1} \Phi(t+1+j) E_{t} \xi(t+1+j) \\
&= \beta E_{t} \xi(t+1)-\beta R(t) \xi(t)+(1-\beta) \sum_{j=0}^{\infty} \Phi(t+1)^{-1} \Phi(t+1+j) E_{t} \xi(t+1+j)- \\
&-(1-\beta) \sum_{j=1}^{\infty} \Phi(t+1)^{-1} \Phi(t+1+j) E_{t} \xi(t+1+j) \\
&= \beta E_{t} \xi(t+1)-\beta R(t) \xi(t)+(1-\beta) E_{t} \xi(t+1) \\
&= E_{t} \xi(t+1)-\beta R(t) \xi(t) .
\end{aligned}
$$

This shows that (12) is the solution of (8). Hence the total consumption function (expenditure function) is given by

$$
\begin{aligned}
c(t)= & (1-\beta) \Phi(t)^{-1} \sum_{j=0} \Phi\left((t+j) E_{t} \xi(t+j)\right)-d_{t}(p(t)) \\
= & -\beta d_{t}(p(t))+(1-\beta)[y(t)+R(t-1) b(t-1)+ \\
& \left.+\sum_{j=1 \tau=0}^{j-1} R(t+\tau)^{-1} E_{t}\left(d_{t+j}(p(t+j))+y(t+j)\right)\right] . \\
w(t)= & R(t-1) b(t-1)+y(t)+\sum_{j=1}^{\infty} \prod_{\tau=0}^{j-1} R(t+\tau)^{-1} E_{t} y(t+1), \\
\vec{d}(t)= & d_{t}(p(t))+\sum_{j=1 \tau=0}^{j-1} R(t+\tau)^{-1} E_{t} d_{t+j}(p(t+j)) .
\end{aligned}
$$

$w(t)$ consists of property income plus the expected present value of nonproperty (labor) income. Thus $w(t)$ can be considered as the permanent income of the consumer. $-\bar{d}(t)$ is the expected present value of minimum-required consumption expenditure; it can be interpreted as the permanent necessary expenditure. Thus (12) and (14) can be rewritten in terms of $w(t)$ and $\bar{d}(t)$ as

$$
\begin{aligned}
& b(t)=R(t-1) b(t-1)+y(t)+d_{t}(p(t))-(1-\beta)[w(t)+\bar{d}(t)] \\
& c(t)=-d_{t}(p(t))+(1-\beta)[w(t)+\bar{d}(t)] .
\end{aligned}
$$

\section{A Class of Dynamic Demand Systems}

\subsection{THE DYNAMIC LINEAR-EXPENDITURE SYSTEM}

The Klein-Rubin-Samuelson (KRS) utility function ${ }^{3}$ is of the form

$$
u(x(t) ; \alpha, \gamma(t))=\sum_{i=1}^{m} \alpha_{i} \log \left(x_{i}(t)+\gamma_{i}(t)\right) \quad\left(\alpha_{i}>0 \& \sum_{i=1}^{m} \alpha_{i}=1\right)
$$

where $\alpha_{i}$ and $\gamma_{i}(t)$ are parameters.

Since the demands for the commodities, in general, vary over time, we may assume that the $\gamma_{i}(t)$ 's vary over time. In Chipman and Tian $(1988 \mathrm{a}, 1988 \mathrm{~b})$ the $\gamma_{i}(t)$ are assumed to have the form

$$
\gamma_{i}(t)=\sum_{l=0}^{n} \gamma_{i} \phi_{l i}(t)
$$

which is a very general form and covers the case of linear trend as well as those of Pollak (1970) and Chipman (1985) as special cases.

The indirect KRS utility function is given by

$$
v(p(t), c(t))=\sum_{i=1}^{m} \alpha_{i} \log \alpha_{i} / p_{i}(t)+\log (p(t) \cdot \gamma(t)+c(t))
$$

which has the form specified by (7) with $d_{t}(p(t))=p(t) \cdot \gamma(t)$. Thus the consumption-savings functions of the DLES are given by (12) and (14) and the demand functions $x_{i}(t)$ of the DLES are 
given by

$$
\begin{aligned}
x_{i}(t)= & \frac{\alpha_{i}}{p_{i}(t)}(p(t) \cdot \gamma(t)+c(t))-\gamma_{i}(t) \\
= & \frac{\alpha_{i}}{p_{i}(t)}(1-\beta)[p(t) \cdot \gamma(t)+y(t)+R(t-1) b(t-1)+ \\
& \left.+\sum_{j=1}^{j-1} R(t+\tau){ }^{-1} E_{t}(p(t+j) \cdot \gamma(t+j)+y(t+j))\right]-\gamma_{i}(t) \\
= & (1-\beta) \frac{\alpha_{i}}{p_{i}(t)}[w(t)+\bar{d}(t)]-\gamma_{i}(t) .
\end{aligned}
$$

Thus the expenditure equations for the DLES are

$$
\begin{aligned}
p_{i}(t) x_{i}(t)= & \alpha_{i}(1-\beta)[p(t) \cdot \gamma(t)+y(t)+R(t-1) b(t-1)+ \\
& \left.+\sum_{j=1 \tau=0}^{-j-1} R(t+\tau)^{-1} E_{t}(p(t+j) \cdot \gamma(t+j)+y(t+j))\right]-p_{i}(t) \gamma_{i}(t) \\
& =(1-\beta) \alpha_{i}[w(t)+\bar{d}(t)]-p_{i}(t) \gamma_{i}(t) .
\end{aligned}
$$

Remark 3. When we let $p(t) \equiv p, R(t) \equiv R$ and $\gamma(t)=\gamma$ over time, the functional forms $(12)-(14)$ are the same as those in Lluch (1973), only the definitions of $w(t)$ and $\bar{d}(t)$ of Lluch are different. This is because Lluch uses a continuous time path, while we use a discrete time path.

\subsection{DYNAMIC GENERALIZED LINEAR EXPENDITURE SYSTEMS}

As we know, the KRS utility function is directly additive, hence there are no specific substitution effects in the LES. We cannot deal with inferior goods (since $\alpha_{i} / p_{i}(t)>0$ ) and complementary goods (since the Slutsky term $\hat{s}_{i j}(t)$ is $>0$ for $i \neq j$ ), nor can we deal with price elasticities whose absolute values exceed unity when $-\gamma_{i}(t)$ is interpreted as the minimum-required quantities (i.e., we need to assume that $\left.\gamma_{i}(t)<0\right)$. We can verify that the GLES also has the same restrictions mentioned above as the LES. Brown and Heien (1972) have modified Sato's (1967) two-level CES production to obtain the utility function which they term the 'S-branch utility tree'. The demand system associated with this utility has the following properties: Specific substitution effects do not necessarily vanish. Goods in the system can be complementary under some conditions. Own-price elasticities are free to vary in the interval $(-\infty, 0)$. Finally, the S-branch utility tree contains the LES and the CES utility function as special cases.

The CES utility function is of the form

$$
u(x(t))=\frac{1}{\rho} \log \left[\sum_{i=1}^{m} \alpha_{i}\left[x_{i}(t)+\gamma_{i}(t)\right]^{p}\right](-\infty<p<1)
$$

which is of course analogous to the CES production function. The utility function is a generalization of the KRS utility function because (16) tends to (15) as $\rho$ tends to zero. The demand functions implied by (16) are also reasonably simple:

$$
x_{i}(t)=\frac{\left(\frac{\alpha_{i}}{p_{i}(t)}\right)^{\alpha}}{\sum_{j=1}^{m}\left(\frac{\alpha_{j}}{p_{j}(t)}\right)^{\alpha} p_{i}(t)}(p(t) \cdot \gamma(t)+c(t))-\gamma_{i}(t)
$$

when the budget constraint is given by

$$
p(t) \cdot x(t)=c(t)
$$

where

$$
\sigma=\frac{1}{1-\rho} .
$$

Brown and Heien (1972) proposed a further generalization of (15) and (16) which they called the $S$-branch utility tree. The consumption goods are assumed to be divided into $S$ branches, with $m$ commodities in the $l$-th branch where the $\sum_{l=1}^{S} m_{l}=m$, so that the utility function can be written as

$$
U(x(t))=\frac{1}{\rho} \log \left(\sum_{l=1}^{s} \alpha_{l}\left[\sum_{i=1}^{m} \alpha_{l i}\left(x_{l i}(t)+\gamma_{l i}(t)^{p_{l}}\right]^{p^{\prime} \rho_{l}}\right)\left(-\infty<\rho_{l},-\infty<\rho<1\right)\right.
$$

which is called the Brown-Heien S-branch utility function. (16) is just the special case of (18) when $s=1$; hence some people call the CES utility function the 1-branch utility function. The parameters $\alpha_{l}$ reflect the importance of the different branches (blocks) in generating total utility the $\alpha_{l i}$, on the other hand, reflect the importance (in generating utility) of particular commoditie within given branches. The $\alpha_{l} s$ and $\alpha_{l i} s$ are all assumed to be positive. The demand functions implied by (18) which were first derived by Brown and Heien (1972) are much more complicated than those implied by (15) or (16). The demand functions are

$$
\begin{aligned}
x_{s i}(t)= & -\gamma_{s i}(t)+\left(\frac{\alpha_{s i}}{p_{s i}(t)}\right)^{\sigma_{s}}\left[a_{s}^{\sigma} X_{s}(t)^{\left(\sigma-\sigma_{s}\right) /\left(\sigma_{s}-1\right)}\right] \times \\
& \times\left(c(t)+\sum_{l=1}^{s} \sum_{j=1}^{m_{l}} p_{l j}(t) \cdot \gamma_{l j}(t)\right) \cdot\left[\sum_{l=1}^{s} a_{l}^{\sigma} X_{l}(t)^{(\sigma-1) /\left(\sigma_{s}-1\right)}\right]^{-1}
\end{aligned}
$$

for $i=1,2, \ldots, m_{s}$ and $s=1,2, \ldots, S$. They satisfy the budget constraint

$$
\sum_{l=1 j=1}^{S} \sum_{l j}^{m_{l}} p_{l j}(t) \cdot x_{l j}(t)=c(t)
$$

Here

$$
\sigma_{s}=\frac{1}{1-p_{s}}
$$

and

$$
X_{l}(t)=\sum_{j=1}^{m_{l}}\left(\frac{\alpha_{l_{j}}}{p_{l_{j}}(t)}\right)^{\sigma_{l}} p_{l_{j}}(t)
$$

A simple derivation can be found in Powell (1974). 
Substituting the demand functions (17) and (19) in (15) and (16) respectively, we obtain

$$
v(p(t), c(t))=\log (c(t)+p(t) \cdot \gamma(t))+\frac{1}{\rho} \log \left(\sum_{i=1}^{m} \alpha_{i}\left(Q_{i}(t)\right)^{\rho}\right)
$$

where

$$
Q_{i}(t)=\frac{\left(\alpha_{i} / p_{i}(t)\right)^{\sigma}}{\sum_{j=1}^{m}\left(\alpha_{j} / p_{j}(t)\right)^{\sigma} p_{i}(t)}
$$

and

$$
\begin{aligned}
v(p(t), c(t))= & \log (c(t)+p(t) \cdot \gamma(t))-\log \left[\sum_{l=1}^{s} a_{l}^{\sigma} X_{l}(t)^{(\sigma-1)\left(\sigma\left(\sigma_{t}-1\right)\right.}\right]+ \\
& +\frac{1}{\rho} \log \left(\sum_{i=1}^{s} a_{l}\left[\sum_{i=1}^{m_{t}} B_{l i}(t)\right]\right)
\end{aligned}
$$

where

$$
B_{l i}(t)=\left(\frac{\alpha_{l i}}{p_{l i}(l)}\right)^{\sigma_{t}}\left[a_{i}^{\sigma} X_{i}(t)^{\left(\sigma_{0}-\sigma_{l}\right)\left(\sigma_{i}-1\right)}\right]
$$

Thus these indirect utility functions have the form specified by (6). Therefore the consumptionsavings functions of the DGLES are given by (12) and (14) and the demand functions of the DGLES with the CES utility function and S-branch utility tree are obtained by substituting (14) in (17) and (19) respectively:

$$
\begin{aligned}
& x_{i}(t)=(1-\beta)(w(t)+\bar{d}(t)) \frac{\left(\alpha_{i} / p_{i}(t)\right)^{\sigma}}{\sum_{j=1}^{m}\left(\alpha_{j} / p_{j}(t)\right)^{\sigma} p_{i}(t)}-\gamma_{i}(t) \\
& x_{s i}(t)=(1-\beta)(w(t)+\bar{d}(t)) \frac{\left(\alpha_{s i} / p_{s i}(t)\right)^{\sigma} a_{s}^{\sigma} X_{s}(t)^{\left(\sigma-\sigma_{s}\right)\left(\sigma_{s}-1\right)}}{\sum_{l=1}^{S} a_{l}^{\sigma} X_{l}(t)^{(\sigma-1)\left(\sigma_{l}-1\right)}}-\gamma_{s i}(t)
\end{aligned}
$$

\subsection{THE DYNAMIC ALMOST IDEAL DEMAND SYSTEM}

The Almost Ideal Demand System (AIDS) was introduced by Deaton and Muellbauer (1980); it has many desirable properties such as furnishing an arbitrary first-order approximation to any demand system, aggregating perfectly over consumers without invoking parallel linear Engel curves, etc. The preferences resulting in the AIDS are the so-called PIGLOG class which are represented via the cost or expenditure function

$$
\log c(v(t), p(t))=(1-v(t)) \log a(p(t))+v(t) \log b(p(t)),
$$

which defines the minimum expenditure necessary to attain a specific utility level at given prices. Here $a(p(t))$ and $b(p(t))$ are linear homogeneous function of within-period prices and given by

$$
\begin{aligned}
& \log a(p(t))=a_{0}(t)+\sum_{i=1}^{m} \alpha_{i} \log p_{i}(t)+\frac{1}{2} \sum_{i=1 j=1}^{m} \sum_{i j}^{m} \gamma_{i j}(t) \log p_{i}(t) p_{j}(t) \\
& \log b(p(t))=\log a(p(t))+\theta_{0} \prod_{i=1}^{m} p_{i}^{\theta_{i}}(t) .
\end{aligned}
$$

From (22), the indirect utility function is given by

$$
v_{t}(p(t), c(t))=\frac{\log c(t)-\log a(p(t))}{\log \frac{b(p(t))}{a(p(t))}}
$$

The demand function can be obtained by the Antonelli-Allen-Roy equation

$$
x_{i}(t)=c(t)\left[\frac{a_{i}^{\prime}(p(t))}{a(p(t))}+\frac{\log \frac{c(t)}{a(p(t))}}{\log \frac{b(p(t))}{a(p(t))}}\left(\frac{b_{i}^{\prime}(p(t))}{b(p(t))}-\frac{a_{i}^{\prime}(p(t))}{a(p(t))}\right)\right],
$$

where $a_{i}^{\prime}(p(t))=\frac{\partial a(p(t))}{\partial p_{i}(t)}$ and $b_{i}^{\prime}(p(t))=\frac{\partial b(p(t))}{\partial p_{i}(t)}$.

In order for the indirect utility function to have the form specified by (7), we assume ${ }^{4}$ $E_{t} p(t+1)=\rho p(t)$. Then $E_{t} p(t+1)=\rho^{t+1} p(0)$ and thus $\log \frac{b\left(E_{t} p(t+1)\right)}{a\left(E_{t} p(t+1)\right)}=\log \frac{b(p(0))}{a(p(0))}$ so that the indirect utility function has the form specified by (7). Thus the consumption-savings functions of the DAIDS are given by (12) and (14) and the demand functions $x_{i}(t)$ of the DAIDS are obtained by substituting (14) in (23).

The demand functions $x_{i}(t)$ for the DIADS are

$$
x_{i}(t)=(1-\beta) w(t)\left[\frac{a_{i}^{\prime}(p(t))}{a(p(t))}+\frac{\log \frac{c(t)}{a(p(t))}}{\log \frac{b(p(t))}{a(p(t))}}\left(\frac{b_{i}^{\prime}(p(t))}{b(p(t))}-\frac{a_{i}^{\prime}(p(t))}{a(p(t))}\right)\right]
$$

\subsection{THE DYNAMIC INDIRECT ADDILOG DEMAND SYSTEM}

The indirect addilog system can be obtained from the indirect additive utility function

$$
v(c(t), p(t))=\log \left[\sum_{i=1}^{m} a_{i}\left(\frac{c(t)}{p_{i}(t)}\right)^{p_{i}}\right] ;\left(b_{i}>-1\right)
$$

where the $a_{i}$ and $b_{i}$ are parameters which are called the preference indicators and coefficients respectively. The resulting demand function is

$$
x_{i}(t)=\frac{a_{i} b_{i} c(t)^{b_{i}} p_{i}(t)^{-\left(b_{i}+1\right)}}{\sum_{j=1}^{m} a_{j} b_{j} c(t)^{b_{j}-1} p_{j}(t)^{-b_{j}}}
$$

In order to obtain the closed-form solution, we consider a special case $b_{i}=b$ for all $i=1,2, \ldots, m$ 
so that (24) becomes

$$
v(c(t), p(t))=b \log c(t)+\log \left(\sum_{i=1}^{m} \frac{a_{i}}{p_{i}\left(t^{b}\right.}\right)
$$

and (25) becomes

$$
x_{i}(t)=\frac{a_{i} c(t) p_{i}(t)^{-(b+1)}}{\sum_{j=1}^{m} a_{j} p_{j}(t)^{-b}} .
$$

The demand functions $x_{i}(t)$ for the DIADS are

$$
x_{i}(t)=(1-\beta) w(t) \frac{a_{i} p_{i}(t)^{-(b+1)}}{\sum_{j=1}^{m} \frac{a_{j}}{p_{j}(t)^{b}}} .
$$

Remark 4. From the above discussion, we know that all of the utility functions considered above can be written in the form $v_{t}(p(t), c(t))=\log g_{t}(p(t))+b \log \left[c(t)+d_{t}(p(t))\right]$, and the solutions for the consumption-savings decision are independent of $g_{1}(p(t))$. Furthermore, we can allow the preferences to change with time periods and the functional forms of the consumption-savings functions are the same as long as the preferences are represented by the above utility functions.

\section{Some Properties of the Dynamic Demand Systems}

We know from the last section that the functional forms of the savings decision function and total consumption expenditures from the DLES, the DGLES, and the DIADS are the same. Only the demand functions for the consumption goods are different for the DLES, the DGLES, and the DIADS. In this section, we analyze responses of historical savings, interest factor, the current and future price to the optimal decision functions, and give elasticities for the DLES, the DGLES and the DIADS. Take the solution functions $b(t), c(t)$ and $x_{i}(t)$ as the functions of $b(t-1), R(t-1), R(t+j), E_{t} y(t+j), E_{t} p(t+j)(j \geqq 0)$, which are denoted $b(t)=\tilde{b}(\cdot), c(t)=\tilde{c}(\cdot)$, and $x_{i}(t)=\tilde{x}_{i}(\cdot)$.

\subsection{PROPERTIES OF THE CONSUMPTION-SAVINGS FUNCTIONS}

We investigate the properties of the following partial derivatives:

$$
\begin{aligned}
\frac{\partial \tilde{b}(\cdot)}{\partial b(t-1)} & =\beta R(t-1) ; \\
\frac{\partial \tilde{b}(\cdot)}{\partial R(t-1)} & =\beta b(t-1) ; \\
\frac{\partial \tilde{b}(\cdot)}{\partial R(t+s)} & =\frac{(1-\beta)}{R(t+s)} \sum_{j=s+1 \tau=0}^{\infty-1} R(t+\tau)^{-1} E_{t} \xi(t+j) \quad(\forall s \geqq 0) ; \\
\frac{\partial \tilde{b}(\cdot)}{\partial y(t)} & =\beta ;
\end{aligned}
$$

$$
\begin{aligned}
\frac{\partial \tilde{b}(\cdot)}{\partial y(t, t+s)} & =-(1-\beta) \prod_{\tau=0}^{s-1} R(t+\tau)^{-1} \quad(\forall s>0) ; \\
\frac{\partial \tilde{b}(\cdot)}{\partial p_{i}(t)} & =\beta \frac{\partial d_{t}(p(t))}{\partial p_{i}(t)} ; \\
\frac{\partial \tilde{b}(\cdot)}{\partial p_{i}(t, t+s)} & =-(1-\beta) \prod_{\tau=0}^{s-1} R(t+\tau)^{-1} \frac{\partial d_{t+s}(p(t, t+s))}{\partial p_{i}(t, t+s)}(\forall s>0) ; \\
\frac{\partial \tilde{c}(\cdot)}{\partial b(t-1)} & =(1-\beta) R(t-1) ; \\
\frac{\partial \tilde{c}(\cdot)}{\partial R(t-1)} & =(1-\beta) b(t-1) ; \\
\frac{\partial \tilde{c}(\cdot)}{\partial R(t+s)} & =-\frac{(1-\beta)}{R(t+s)} \sum_{j=s+1 \tau=0}^{j-1} R(t+\tau)^{-1} E_{i} \xi(t+j) \quad(\forall s>0) ; \\
\frac{\partial \tilde{c}(\cdot)}{\partial y(t)} & =(1-\beta) ; \\
\frac{\partial \tilde{c}(\cdot)}{\partial y(t, t+s)} & =(1-\beta) \prod_{\tau=0}^{s-1} R(t+\tau)^{-1} \quad(\forall s>0) ; \\
\frac{\partial \tilde{c}(\cdot)}{\partial p_{i}(t)} & =-\beta \frac{\partial d_{t}(p(t))}{\partial p_{i}(t)} ; \\
\frac{\partial \tilde{c}(\cdot)}{\partial p_{i}(t, t+s)} & =(1-\beta) \prod_{\tau=0}^{s-1} R(t+\tau)^{-1} \frac{\partial d_{t+s}(p(t, t+s))}{\partial p_{i}(t, t+s)}(\forall s>0) .
\end{aligned}
$$

The above derivatives show that an increase in the past-period bondholdings $b(t-1)$ causes the current-period bondholdings $b(t)$ and the current total consumption expenditure $c(t)$ to increase. An increase in the last-period interest factor $R(t-1)$ causes the current-period savings and the current total consumption expenditure to decrease if the consumer was borrowing the last period (i.e., $b(t-)<0$ ) or to increase otherwise; an increase in a future interest factor causes the currentperiod savings to increase and the current total consumption expenditure to decrease. An increase in the current labor income $y(t)$ causes the current-period savings and total consumption to increase. An increase in the future expected labor income causes the current-period savings to decrease and the current total consumption expenditure to increase. An increase in the currentperiod price of the $j$ th good causes the current-period savings to decrease (increase) and causes the total consumption expenditure to increase (decrease) if $\frac{\partial d_{1}(p(t))}{\partial p_{j}(t)}$ is negative (positive). An increase in the future expected price of the $i$ th good causes the current-period savings to increase and the current total consumption expenditure to decrease if $\frac{\partial d_{t}(p(t))}{\partial p_{i}(t)}$ is negative, and causes the current-period savings to decrease and the current total consumption expenditure to increase if $\frac{\partial d_{t+s}(p(t))}{\partial p_{i}(t, t+s)}$ is positive. 


\subsection{PROPERTIES OF DEMAND FUNCTIONS OF THE DYNAMIC DEMAND SYSTEMS}

Now we study the properties of the demand functions of the dynamic demand systems, and particularly the vectors of partial derivatives of the demand functions with respect to $b(t-1), R(t-1), R(t+j), E_{t} y(t+j), E_{t} p(t+j)(j \geqq 0)$. Here we only give the properties of the demand functions of the DLES and DGLES. The demand functions of the DAIDS and the DIADS can be similarly studied.

4.2.1 Properties of the DLES. For the DLES, we have

$$
\begin{aligned}
& \frac{\partial \tilde{x}_{i}(\cdot)}{\partial b(t-1)}=(1-\beta) R(t-1) \frac{\alpha_{i}}{p_{i}(t)}>0 ； \\
& \frac{\partial \tilde{x}_{i}(\cdot)}{\partial R(t-1)}=(1-\beta) b(t-1) \frac{\alpha_{i}}{p_{i}(t)}\left\{\begin{array}{ll}
\geqq 0 & \text { if } b(t-1) \geqq 0 \\
<0 & \text { otherwise }
\end{array} ;\right. \\
& \frac{\partial \tilde{x}_{i}(\cdot)}{\partial R(t+s)}=-\frac{(1-\beta) \alpha_{i}}{R(t+s) p_{i}(t)} \sum_{j=s+1}^{\infty} \prod_{\tau=0}^{j-1} R(t+\tau)^{-1} E_{t} \xi(t+j)<0(\forall s>0) \\
& \frac{\partial \tilde{x}_{i}(\cdot)}{\partial y(t)}=(1-\beta) \frac{\alpha_{i}}{p_{i}(t)}>0 ; \\
& \frac{\partial \tilde{x}_{i}(\cdot)}{\partial y(t, t+s)}=(1-\beta) \frac{\alpha_{i}}{p_{i}(t)} \prod_{\tau=0}^{s-1} R(t+\tau)^{-1}>0 ; \\
& \frac{\partial \tilde{x}_{i}(\cdot)}{\partial p_{j}(t)}=(1-\beta) \frac{\alpha_{i} \gamma_{j}(t)}{p_{i}(t)}\left\{\begin{array}{ll}
\geqq 0 & \text { if } \gamma^{(t)} \geqq 0 \\
<0 & \text { otherwise }
\end{array} ;\right. \\
& \left.\frac{\partial \tilde{x}_{i}(\cdot)}{\partial p_{i}(t)}=-\frac{x_{i}(t)}{p_{i}(t)}-\left[1-(1-\beta) \alpha_{i}\right)\right] \frac{\gamma_{i}(t)}{p_{i}(t)}\left\{\begin{array}{ll}
\leqq 0 & \text { if } \gamma_{i}(t) \geqq\left(x_{i}(t)\right) /\left(1-(1-\beta) \alpha_{i}\right) \\
<0 & \text { otherwise }
\end{array} ;\right. \\
& \frac{\partial \tilde{x}_{i}(\cdot)}{\partial p_{j}(t, t+s)}=(1-\beta) \frac{\alpha_{i}}{p_{i}(t)} \prod_{\tau=0}^{s-1} T(t+\tau)^{-1} \gamma_{j}(t+s)\left\{\begin{array}{ll}
\geqq 0 & \text { if } \gamma_{j}(t+s) \geqq 0 \\
<0 & \text { otherwise }
\end{array} \text { for any } s>0 .\right.
\end{aligned}
$$

The interpretations for the above derivatives is similar to those in Section 4.1. In the following, we give some elasticity formulae for the GLES. The price elasticities are given by

$$
\begin{aligned}
& \eta_{i i}(t)=\frac{d \log \tilde{x}_{i}(\cdot)}{d \log p_{i}(t)}=-1-\left[1-(1-\beta) \alpha_{i}\right] \frac{\gamma_{i}(t)}{x_{i}(t)} ; \\
& \eta_{i j}(t)=(1-\beta) \frac{\alpha_{i} \gamma_{j}(t) p_{j}(t)}{p_{i}(t) x_{i}(t)}
\end{aligned}
$$

The total expenditure elasticity $\partial \log \tilde{x}_{i}(\cdot) / \partial \log c(t)$ is

$$
E_{c}^{i}(t)=\frac{\alpha_{i}}{p_{i}(x) x_{i}(t)}[-p(t) \cdot \gamma(t)+(1-\beta)(w(t)+\bar{d}(t))] .
$$

The permanent income elasticity $\partial \log \tilde{x}_{i}(\cdot) / \partial \log w(t)$ is

$$
E_{w}^{i}(t)=\frac{\alpha_{i}(1-\beta) w(t)}{p_{i}(t) x_{i}(t)} .
$$

Denote by $\tilde{x}_{i}(\cdot)=h_{i}(p(t), c(t))$. Then, the Slutsky terms

$$
\hat{s}_{i j}(t)=\frac{\partial h_{i}(p(t), c(t))}{\partial p_{j}(t)}+\frac{\partial h_{i}(p(t), c(t))}{\partial c(t)} h_{j}(p(t), c(t))
$$

are given by

$$
\begin{aligned}
& \hat{s}_{i i}(t)=-\left(1-\alpha_{i}\right)\left(x_{i}(t)+\gamma_{i}(t)\right) / p_{i}(t)<0 \\
& \hat{s}_{i j}(t)=\frac{\alpha_{i}\left(x_{j}(t)+\gamma_{j}(t)\right)}{p_{j}(t)}>0
\end{aligned}
$$

which are identically the same in the LES.

4.2.2 Properties of the DGLES. Since the CES utility function is a special case of the BrownHeien utility function $(s=1)$, the demand function determined by $(20)$ is the same as the one determined by $(21)$ when $s=1$. So we only investigate the derivatives of the demand function given by (21).

Let

$$
D_{s i}(t)=(1-\beta)\left(\frac{\alpha_{s i}}{p_{s i}(t)}\right)^{\sigma_{t}} \frac{a_{s}^{\sigma} X_{s}(t)^{\left(\sigma-\sigma_{s}\right) /\left(\sigma_{t}-1\right)}}{\sum_{l=1}^{s} a_{l}^{\sigma} X_{l}(t)^{(\sigma-1) /\left(\sigma_{l}-1\right)}}
$$

Then

$$
\begin{aligned}
\frac{\partial \tilde{x}_{s i}(\cdot)}{\partial b(t-1)} & =D_{s i}(t) R(t-1)>0 ; \\
\frac{\partial \tilde{x}_{s i}(\cdot)}{\partial R(t-1)} & =D_{s i}(t) b(t-1) \begin{cases}\geqq 0 & \text { if } b(t-1) \geqq 0 \\
<0 & \text { otherwise } ;\end{cases} \\
\frac{\partial \tilde{x}_{s i}(\cdot)}{\partial R(t, t+v)} & =-\frac{D_{s i}(t)}{R(t+v)} \sum_{v+1 \tau=1}^{-j-1} \prod_{t=1}^{j-1} R(t+\tau)^{-1} \xi(t+j)<0 \quad(\forall v>0) ; \\
\frac{\partial \bar{x}_{s i}(\cdot)}{\partial y(t)} & =D_{s i}(t)>0 ; \\
\frac{\partial \tilde{x}_{s i}(\cdot)}{\partial y(t, t+v)} & =D_{s i}(t) \prod_{\tau=0}^{v-1} R(t+\tau)^{-1}>0 \quad(\forall v>0) .
\end{aligned}
$$

Since the $\tilde{x}_{i}(\cdot)=h_{i}(p(t), c(t))$ for the DGLES have identically the same functional forms as in the GLES, the total consumption expenditure elasticities $E_{c}^{s i}(t)$ and Slutsky terms of the DGLES should be the same as those in the GLES. Therefore, we have

$$
\begin{gathered}
E_{c}^{x i}(t)=\frac{\left(x_{s i}(t)+\gamma_{s i}(t)\right)}{x_{s i}(t)} \frac{c(t)}{(c(t)+\gamma(t))} \\
\hat{s}_{l, l j}(t)=\frac{\left(x_{s i}(t)+\gamma_{s i}(t)\right)\left(x_{i j}(t)+\gamma_{i j}(t)\right)}{(c(t)+\gamma(t))} \sigma
\end{gathered}
$$

for $l \neq s$ 


$$
\begin{aligned}
\hat{s}_{s i t, j}(t)= & \frac{\left(x_{s i}(t)+\gamma_{s i}(t)\right)\left(x_{s j}(t)+\gamma_{s j}(t)\right)}{(c(t)+\gamma(t))} \sigma- \\
& -\frac{\left(x_{s i}(t)+\gamma_{s i}(t)\right)\left(\sigma-\sigma_{s}\right)\left(x_{s j}(t)+\gamma_{s j}(t)\right)}{\left(c_{s}(t)+\sum_{i=1}^{m_{s}} p_{s i}(t) \cdot \gamma_{s i}(t)\right)}
\end{aligned}
$$

for $l=s, i \neq j$, where $s, r$ denote the blocks, $i=1,2, \ldots, m_{s}$ and $j=1,2, \ldots, m_{l}$.

$$
c_{s}(t)=\sum_{i=1}^{m} p_{s i}(t) x_{s i}(t)
$$

The derivation for these formulas can be found in Brown and Heien (1972).

\section{Simplification of the Optimal Decision Functions}

To specialize the optimal decision functions, we have to be more explicit about the interest rate the prices and labor income. For simplicity, we assume that the expected interest factor is constant over time, and that the expected prices and labor income obey

$$
\begin{aligned}
& E_{t} p(t+1)=\rho p(t) \\
& E_{t} y(t+1)=\theta(y(t)-\bar{y})+\bar{y}
\end{aligned}
$$

or

$$
\begin{aligned}
& p(t+1)=\rho p(t)+\varepsilon(t+1) \\
& y(t+1)=\theta(y(t)-\bar{y})+\bar{y}+u(t+1)
\end{aligned}
$$

where $\varepsilon(t+1)$ and $u(t+1)$ are assumed to be independently, identically distributed and $E_{t} \varepsilon(t+1)=E_{t} u(t+1)=0$. Then

$$
\begin{aligned}
& E_{t} p(t+j)=\rho^{j} p(t) \quad(j>0) ; \\
& E_{\imath} y(t+j)=\theta^{j}(y(t)-\bar{y})+\bar{y} \quad(j>0) .
\end{aligned}
$$

Therefore, (12) and (14) become respectively

$$
\begin{aligned}
b(t)= & \beta R b(t-1)+\beta \xi(t)-(1-\beta) \sum_{j=1}^{\infty} R^{-j}\left(\rho^{j} p(t) \cdot \gamma(t)+\theta^{j}(\gamma(t)-\bar{y})+\bar{y}\right) \\
= & \beta R b(t-1)+p(t) \cdot \gamma(t) \frac{\beta R-\rho}{R-p}+y(t) \frac{\beta R-\theta}{R-\theta}+(1-\beta) \bar{y} \frac{R(\theta-1)}{(R-\theta)(R-1)} \\
c(t)= & (1-\beta) R b(t-1)-p(t) \cdot \gamma(t) \frac{\beta R-\rho}{R-\rho}+y(t) \frac{R(1-\beta)}{R-\theta}- \\
& -(1-\beta) \bar{y} \frac{R(\theta-1)}{(R-\theta)(R-1)} .
\end{aligned}
$$

The demand functions of the DLES, the DGLES, the DAIDS, and the DIADS are then given by

$$
\begin{aligned}
x_{i}(t)= & (1-\beta) \frac{\alpha_{i} R}{p_{i}(t)}\left(b(t-1)+\frac{1}{R-\rho} p(t) \cdot \gamma(t)+\frac{1}{R-\theta} y(t)+\frac{\theta-1)}{(R-\theta)(R-1)} \bar{y}\right)-\gamma_{i}(t) ; \\
x_{s i}(t)= & -\gamma_{i}(t)+(1-\beta) R \frac{\left(\frac{\alpha_{s i}}{p_{s i}(t)}\right)^{\sigma_{s}}\left[a_{s}^{\sigma} X_{s}(t)^{\left(\sigma-\sigma_{s}\right)\left(\sigma_{s}-1\right)}\right]}{\sum_{t=1}^{S}\left(\alpha_{t}\right)^{\sigma}\left(X_{t}(t)\right)^{(\sigma-1)\left(\sigma_{t}-1\right)}} \times \\
& \times\left[b(t-1)+\frac{p(t) \cdot \gamma(t)}{R-p)}+\frac{y(t)}{R-\theta}+\frac{(\theta-1) \bar{y}}{(R-\theta)(R-1)}\right] ; \\
x_{i}(t)= & {\left[\frac{a_{i}(p(t))}{a(p(t))}+\frac{\log \frac{c(t)}{a(p(t))}}{\left.\log \frac{b(p(t))}{a(p(t))}\left(\frac{b_{i}(p(t))}{b(p(t))}-\frac{a_{i}(p(t))}{a(p(t))}\right)\right] \times}\right.} \\
& \times\left[b(t-1)+\frac{p(t) \cdot \gamma(t)}{R-p}+\frac{y(t)}{R-\theta}+\frac{(\theta-1) \bar{y}}{(R-\theta)(R-1)}\right] ; \\
x_{i}(t)= & \frac{(1-\beta) R a_{i} p_{i}(t)^{-(b+1)}\left(b(t-1)+\frac{y(t)}{(R-\theta)}+\frac{(\theta-1) \bar{y}}{(R-\theta)(R-1)}\right)}{\sum_{j=1}^{m} \frac{a_{j}}{p_{j}(t)^{b}}} .
\end{aligned}
$$

The permanent income and permanent indispensable expenditure are given respectively by

$$
\begin{aligned}
& w(t)=R\left[b(t-1)+\frac{1}{R-\theta} y(t)+\frac{1-\theta}{(R-1)(R-\theta)} \bar{y},\right. \\
& \bar{d}(t)=\frac{R}{R-\rho} d_{i}(p(t)) .
\end{aligned}
$$

The theoretical analysis can be similarly studied for the simplified decision functions. We omit it here.

\section{Conclusions}

In this paper, we have derived the consumption-savings decision functions and demand functions from the consumer's intertemporal maximization problem over discrete time for a class of utility functions, namely the Klein-Rubin-Samuelson (KRS) utility function, the CES utility function, the Brown-Heien S-branch utility tree, the PIGLOG class of preferences, and Houthakker's indirect addilog utility function. Theoretical analysis was also provided in this paper. We generalized the Klein-Rubin linear expenditure system, Wales's generalized linear expenditure system, Brown and Heien's generalization of the linear expenditure system, the Almost Ideal 
Demand System, and Houthakker's indirect addilog demand system to include the consumptionsavings decisions. Since the explicit forms for the optimal decision functions were obtained, these may be easy to use in empirical applications.

\section{Notes}

* Work supported by NSF grant SES-8607652. The comments and suggestions of an anonymous referee of this Volume greatly improved the paper.

1. The inequality in the budget constraint can be removed by assuming preferences to be locally nonsatiated. Note that if the stochastic budget constraint holds with equality, so must the expected budget constraint.

2. Extension to the general case where $b$ varies with time is possible but the exposition is simpler if attention is restricted to the case where $b$ is constant over time.

3. We use this terminology in place of the widespread 'Stone-Geary utility function' used by Powell (1973) and which apparently derives from Brown and Heien (1972), who referred to the LES as the 'Stone-Geary linear expenditure system'. This attribution is simply not accurate and we do not wish to perpetuate it The form (15) was first obtained by Samuelson (1948) upon integrating the LES dem punctions first proposed by Klein and Rubin (1948) Re tam (1954) pesened (1954) presented his work as an empirical implementation of the Klein-Rubin (1948) LES, and referred to Samuelson's (1948) result but not to Geary's (1949).

4. As was pointed out in footnote 2, we can still obtain closed-form solutions even if this assumption is dropped.

References

Allais, M.: 1953, 'Le comportement de l'homme devant le risque; critique des postulats et axiomes de l'école américaine', Econometrica, 21, 503-546.

Anderson, G., and R. Blundell: 1985, 'Empirical Approaches to Dynamic Consumer Demand Behavior', Working Paper No. 85-23, Department of Economics, McMaster University, Hamilton, Ontario, Canada.

Anderson, G., and M. Browning: 1986, 'Allocating Expenditure: Demand Systems and the Consumption Function, an Integrated Approach', Working Paper No. 86--07, Department of Economics, McMaster University, Hamilton, Ontario, Canada.

Barten, A. P.: 1969, 'Maximum Likelihood Estimation of a Complete System of Demand Equations', European Economic Review, 1, 7-73.

Ben-Tal, A., and A. Ben-Israel: 1987, 'A Recourse Certainty Equivalent for Decisions under Uncertainty', Department of Industrial Engineering, University of Michigan, Ann Arbor, Michigan, U.S.A.

Blackorby, C., R. Boyce, and R. R. Russell: 1978, 'Estimation of Demand Systems Generated by the Gorman Polar Form; A Generalization of the S-Branch Utility Tree,' Econometrica, 46, 345-363.

Brown, M., and D. M. Heien: 1972, 'The S-branch Utility Tree: A Generalization of the Linear Expenditure System', Econometrica, 40, 737-747.

Chipman, J. S.: 1985, 'Estimation of Net-Import Demand Functions for the Federal Republic of Germany, 1959-1982', in H. Giersch (ed.), Probleme und Perspektiven der weltwirtschaftlichen Entwicklung, Jahrestag des Vereins für Socialpolitik, Duncker \& Humblot, Berlin, Germany, pp. 197-213.

Chipman, J. S. and G. Tian: 1988b, 'Generalized Maximum-Likelihood Estimation of the Linear Expenditure System', manuscript.

Chipman, J. S. and G. Tian: 1988c, 'A General-Equilibrium Intertemporal Model of An Open Economy', manuscript.

Chipman, J. S. and G. Tian: 1989, 'Stochastic Specification and Maximum-Likelihood Estimation of the Linear Expenditure System', in B. Raj (ed.), Advances in Econometrics and Modelling, Kluwer Academic Publishers, Dordrecht, the Netherlands, pp.131-142.

Christensen, L. R., D. W. Jorgenson, and L. J. Lau: 1975, 'Transcendental Logarithmic Utility Functions', American Economic Review, 65, 367-383.

Epstein, Z., and K. I. Wolpin: 1988, 'Dynamic Labor Force Participation of Married Women and Endogenous Work Experience', typescript.

Deaton, A., and J. Muellbauer: 1980, 'An Almost Ideal Demand System', American Economic Review, 70, 312-326. 
Geary, R.C.: 1949, 'A Note on “A Constant-Utility Index of the Cost of Living”, Review of Economic Studies, 18, 65-66.

Goldberger, A. S., and T. Gamaletsos: 1970, 'A Cross-Country Comparison of Consumer Expenditure Pattems', European Economic Review, 1, 357-400.

Hall, R. E.: 1978, 'Stochastic Implications of the Life-Cycle Permanent-Income Hypotheses: Theory and Evidence', Journal of Political Economy, 86, 971-987.

Hicks, J. R.: 1935, 'Wages and Interest: The Dynamic Problem' , Economic Journal, 45, 456-468. Hicks, J. R.: 1939, Value and Capital, Clarendon Press, Oxford, England.

Houthakker, H. S.: 1960, 'Additive Preferences', Econometrica, 28, 244-257.

Howe, H.: 1974, Estimation of the Linear and Quadratic Expenditure Systems: A Cross-Section Case for Colombia, Ph. D. dissentation, University of Pennsylvania, Philadelphia, Pennsylvania, U.S.A.

Howe, H.: 1975, 'Development of the Extended Linear Expenditure System from Simple Saving Assumptions', European Economic Review, 6, 305-310.

Johansen, L:: 1969, 'On the Relationship between some Systems of Demand Functions', Liiketaloudellinen Aikakauskirja, 18, 30-41.

Kahneman, D., and A. Tversky: 1979, 'Prospect Theory: An Analysis of Decision under Risk', Econometrica, 47, 263-291.

Klein, L. R., and H. Rubin: 1948, 'A Constant-Utility Index of the Cost of Living', Review of Economic Studies, 15, 84-87.

Lluch, C.: 1973, 'The Extended Linear Expenditure System', European Economic Review, 4, 21-32.

Lluch, C.: 1974, 'Expenditure, Savings and Habit Formation', International Economic Review, 15 786-797.

Lluch, C., and M. Morishima: 1973, 'Demand for Commodities under Uncertain Expectation', in M. Morishima, et al., Theory of Demand, Real and Monetary, Clarendon Press, Oxford, England, pp. 169-183.

Lluch, C., A. A. Powell, and R. A. Williams: 1977, Patterns in Household Demand and Saving, Oxford University Press, New York, New York, U.S.A.

Lucas, R. E.: 1982, 'Interest Rates and Currency Prices in a Two-Country World', Journal of Monetary Economics, 10, 335-359.

Machina, M. J.: 1982, “"Expected utility" Analysis without the Independence Axiom', Econometrica, 50, 277-323.

MacKinnon, J. G.: 1976, 'Estimating the Linear Expenditure System and its Generalizations', in S. M. Goldfeld and R. E. Quandt (eds.), Studies in Nonlinear Estimation, Lippincott, Ballinger Cambridge, Massachusetts, U.S.A., pp. 143-166.
MaCurdy, T. E.: 1983, 'A Simple Scheme for Estimating an Intertemporal Model of Labor Supply and Consumption in the Presence of Taxes and Uncertainty', International Economic Review, 24, 265-289.

Marschak, J.: 1950, 'Rational Behavior, Uncertain Prospects, and Measurable Utility', Econometrica, 18, 111-141.

Modigliani, F., and R. Brumberg: 1964, 'Utility Analysis and the Consumption Function: An Interpretation of Cross-Section Data', in Post Keynesian Economics, K. K. Kurihara (ed.), Rutgers University Press, New Brunswick, New Jersey, U.S.A.,pp. 388-436.

Musgrove, P.: 1974, Determination and Distribution of Permanent Household Income in Urban South America, Ph. D. dissertation, Massachusetts Institute of Technology, Cambridge, Massachusetts, U.S.A.

Musgrove, P.: 1977, 'An Extended Linear Permanent Expenditure System (ELPES)', in A. S. Blinder and P. Friedman (eds.), Natural Resources, Uncertainty, and General Equilibrium Systems, Essays in Memory of Rafael Lusky, Academic Press, New York, New York, U.S.A., 241-255.

Neumann, J. von, and O. Morgenstem: 1947, Theory of Games and Economic Behavior, 2nd ed., Princeton University Press, Princeton, New Jersey, U.S.A.

Parks, R. W.: 1969, 'Systems of Demand Equations: An Empirical Comparison of Altemative Functional Forms', Econometrica, 37, 629-650.

Parks, R. W.: 1971, 'Maximum-Likelihood Estimation of the Linear Expenditure System', Journal of the American Statistical Association, 66, 900-903.

Pollak, R. A., and T. J. Wales: 1969, 'Estimation of the Linear Expenditure System', Econometrica, 37, 611-628.

Pollak, R. A.: 1970, 'Habit Formation and Dynamic Demand Functions', Journal of Political Economy, 78, 745-763.

Powell, A.: 1973, 'Estimation of Lluch's Extended Linear Expenditure System from CrossSectional Data', Australian Journal of Statistics, 15, 111-117.

Powell, A.: 1974, Empirical Analytics of Demand Systems, Heath, Lexington, Massachusetts, U.S.A.

Ronning, G.: 1983, 'A Note on Barten's Result Conceming the Estimation of Share Equations', Postfach 5560, Universităt Konstanz, D-7750 Konstanz.

Ramsey, F. P.: 1928, 'A Mathematical Theory of Saving', Economic Journal, 38, 543-559.

Samuelson, P. A.: 1948, 'Some Implications of "Linearity"', Review of Economic Studies, 15, 88-90.

Samuelson, P. A.: 1953, 'Utilité, préference et probabilité, in Econométrie, Paris: Centre National de la Recherche Scientifique, Colloques Internationaux, XL, 141-150. English translation: 1966, 'Utility, Preference, and Probability', in J. E. Stiglitz (ed.), The Collected Scientific Papers of P. A. Samuelson, The MIT Press, Cambridge, Massachusetts, U.S.A., Vol. 1, 127. 136. 
Sargent, T. J.: 1979, Macroeconomic Theory, Academic Press, New York, New York, U.S.A.

Sargent, T. J.: 1987, Dynamic Macroeconomic Theory, Harvard University Press, Cambridge, Massachusetts, U.S.A.

Sato, K.: 1972, 'Additive Utility Functions with Double-Log Consumer Demand Functions', Journal of Political Economy, 80, 102-124.

Simon, H. A.: 1956, 'Dynamic Programming under Uncertainty with a Quadratic Criterion Function', Econometrica, 24, 74-81.

Stone, R.: 1954, 'Linear Expenditure Systems and Demand Analysis: An Application to the British Pattem of Demand', Economic Journal, 64, 511-527.

Theil, H.: 1954, 'Econometric Models and Welfare Maximization', Weltwirtschaftliches Archiv, 72, 60-83.

Theil, H.: 1957, 'A Note on Certainty Equivalence in Dynamic Programming', Econometrica, 25, 346-349.

Theil, H.: 1965, 'The Information Approach to Demand Analysis', Econometrica, 33, 67-87.

Theil, H.: 1986, Theory and Measurement of Consumer Demand, Vols. 1 and 2, North-Holland, Amsterdam, Holland.

Tintner, G.: 1938a, 'The Maximization of Utility over Time', Econometrica, 6, 154-158.

Tintner, G.: 1938b, 'The Theoretical Derivation of Dynamic Demand Curves', Econometrica, 6, 375-380.

Wales, T.: 1971, 'A Generalized Linear Expenditure Model of the Demand for Nondurable Goods in Canada', Canadian Journal of Economics, 4, 471-484.

Wales, T. J. and A. D. Woodland: 1983, 'Estimation of Consumer Demand System with Binding Non-Negativity Constraints', Journal of Econometrics, 21, 263-285.

Wold, H. O. A.: 1952, 'Ordinal Prefenence or Cardinal Utility?', Econometrica, 20, 661-664.

Woodland, A. D.: 1979, 'Stochastic Specification and the Estimation of Share Equations', Journal of Econometrics, 10, 361-383.

Yaari, M. E.: 1987, 'The Dual Theory of Choice under Risk', Econometrica, 55, 95-115. 